\title{
FAST SPEED RESPONSE FIELD-ORIENTATION CONTROL OF INDUCTION MOTOR DRIVE WITH ADAPTIVE NEURAL INTEGRATOR
}

\author{
Md. Abdur RAFIQ \\ Mohammed Golam SARWER \\ Department of Electrical \& Electronic Engineering \\ Khulna University of Engineering \& Technology \\ Khulna-9203, Bangladesh. \\ E-mail: saku@eee.kuet.ac.bd
}

B. C. GHOSH

\begin{abstract}
This paper presents a novel fast speed response control strategy for the poly-phase induction motor drive system based on flux angle. The control scheme is derived in rotor field coordinates and employs the estimation of the rotor flux and its position. An adaptive notch filter is proposed to eliminate the dc component of the integration of signals used for the rotor flux estimation. To improve the performance of the rotor flux estimator derivative term of the back emf is incorporated in the system. The voltage components in the synchronous reference frame are generated in the controller considering back emf and steady state voltage drops and transformed to stationary reference frame for driving the motor. Simulation of the drive system was carried out and the results were compared with those obtained for a system that produces the above mentioned voltage components using conventional PI controller. It is observed that the proposed control methodology provides faster response than the conventional PI controller incorporated system.
\end{abstract}

Keywords: Field-orientation control, neural integrator and induction motor.

\section{INTRODUCTION}

After the introduction of power electronics in industrial control, research was going on to use induction motors for high performance applications such as machine tools, robotics, etc. It was F.Blaschke [1] and K.Hasse [2] who first proposed the vector control methodologies for induction motors. Blaschke [1] proposed the direct method of field orientation and Hasse [2] introduced the indirect method of field orientation control. The technology has been developed and improved over the last three decades and at present it is in the matured stage.
A detailed explanation of this theory is given in [3].

The field-oriented control (FOC) technique is widely used in high performance motion control of induction motors. Because of torque/flux decoupling, FOC achieved good dynamic response and accurate motion control as separately excited dc motors. However, in realtime implementation, precise decoupling which requires accurate motor parameters cannot be completely achieved due to significant plant uncertainties. These uncertainties include external disturbances, unpredictable parameter variations, and unmodeled plant nonlinear dynamics. Consequently, this deteriorates the 
dynamic performance of flux and speed significantly. Generally speaking, the performance of this control system depends on the accuracy of the mathematical model of induction motor [5].

The control strategy of Field-orientation control is normally developed on the basis of estimation of induction motor flux. The estimators are designed using current or voltage models of the motor. The current model is highly sensitive to motor parameters. On the other hand, integration or low pass filter-based flux estimators introduce error due to dc offset value [6] \& [7]. To solve the problem notch filter is introduced in [6]. The same methodology is applied through adaptive integration ANN estimators are given in [7]. This method is highly speed and back emf sensitive and needs some modifications. A flux observer has been proposed in [8] is reported to be insensitive to stator resistance variation. Sliding mode observer design has been employed in the method.

High performance control scheme for poly-phase induction motor drives are implemented in different forms such as (i) direct torque control (ii) direct field-orientation control (iii) indirect field-orientation control (iv) field- acceleration method and (v) model reference adaptive control. The model reference speed sensorless control in [9] considers the field orientation model of the poly-phase induction motor. It does not require any sensor for speed or rotor flux. Control theory developed on the basis of angle between flux and stator $\mathrm{mmf}$ is proposed in [10]. It is reported that load angle control simplifies the control strategy. DSP-based implementation using fieldprogrammable gate array is adopted for laboratory. Superior operating performance for the induction motor drive system can be achieved by combining the aspects of variable structure control, direct torque control and space vector modulation [11]. In this strategy the observer used is a sliding mode one, the main control aspect is direct torque control and the drive system is implemented in a DSP-based system.

This paper presents a fast speed response control strategy for the induction motor filed orientation control. The control scheme is derived in rotor field co-ordinates. On the other hand, a neural network based adaptive integration methodology is proposed for rotor flux estimation. Estimated flux is obtained from back emf by an integration method accomplished by programmable cascaded low pass ( PCLPF) implement by hybrid neural network consisting of recurrent neural network ( $\mathrm{RNN}$ ) and a feed-forward artificial neural network( FFANN).

\section{MATHEMATICAL MODEL}

The fifth order nonlinear state space model of induction motor is represented in the synchronous reference frame (d-q) by as follows: [4]

$v_{d s}=\left(R_{s}+p L_{s}\right) i_{d s}-L_{s} \omega_{e} i_{q s}+p L_{m} i_{d r}-L_{m} \omega_{e} i_{q r}$

(1)

$$
\begin{aligned}
& v_{q s}=\omega_{e} L_{s} i_{d s}+\left(R_{s}+p L_{s}\right) i_{q s}+L_{m} \omega_{e} i_{d r}+p L_{m} i_{q r} \\
& 0=p L_{m} i_{d s}-\omega_{s l} L_{m} i_{q s}+\left(R_{r}+p L_{r}\right) i_{d r}-L_{r} \omega_{s l} i_{q r} \\
& 0=L_{m} \omega_{s l} i_{d s}+p L_{m} i_{q s}+\left(R_{r}+p L_{r}\right) i_{q r}+L_{r} \omega_{s l} i_{d r} \\
& T_{e m}=J p \omega_{r}+B \omega_{r}+T_{L}
\end{aligned}
$$

Where, $\omega_{e}, \omega_{r}$ and $\omega_{s l}\left(=\omega_{e}-\omega_{r}\right)$ are the synchronous, rotor and slip angular speeds respectively, $\quad p(=d / d t)$ is the differential operator and $L_{m}$ is the mutual inductance.

The electromagnetic torque in terms of $d$ - and $q$ axes components

$$
T_{e m}=\frac{3}{2} P_{p} L_{m}\left(i_{q s} i_{d r}-i_{d s} i_{q r}\right)
$$

Where $P_{p}$ is the number of poles.

Components of rotor flux are

$$
\begin{aligned}
& \lambda_{d r}=L_{r} i_{d r}+L_{m} i_{d s} \\
& \lambda_{q r}=L_{r} i_{q r}+L_{m} i_{q s}
\end{aligned}
$$

From Eqn (7) and Eqn (8), $d$ - and $q$ - axes rotor currents are

$$
\begin{aligned}
& i_{d r}=\frac{1}{L_{r}}\left(\lambda_{d r}-L_{m} i_{d s}\right) \\
& i_{q r}=\frac{1}{L_{r}}\left(\lambda_{q r}-L_{m} i_{q s}\right)
\end{aligned}
$$

Substituting Eqn (7-10) into Eqn (3) and Eqn (4) yields

$$
\begin{aligned}
& \frac{d \lambda_{d r}}{d t}+\frac{R_{r}}{L_{r}} \lambda_{d r}-\frac{L_{m}}{L_{r}} R_{r} i_{d s}-\omega_{s l} \lambda_{q r}=0 \\
& \frac{d \lambda_{q r}}{d t}+\frac{R_{r}}{L_{r}} \lambda_{q r}-\frac{L_{m}}{L_{r}} R_{r} i_{q s}+\omega_{s l} \lambda_{d r}=0
\end{aligned}
$$




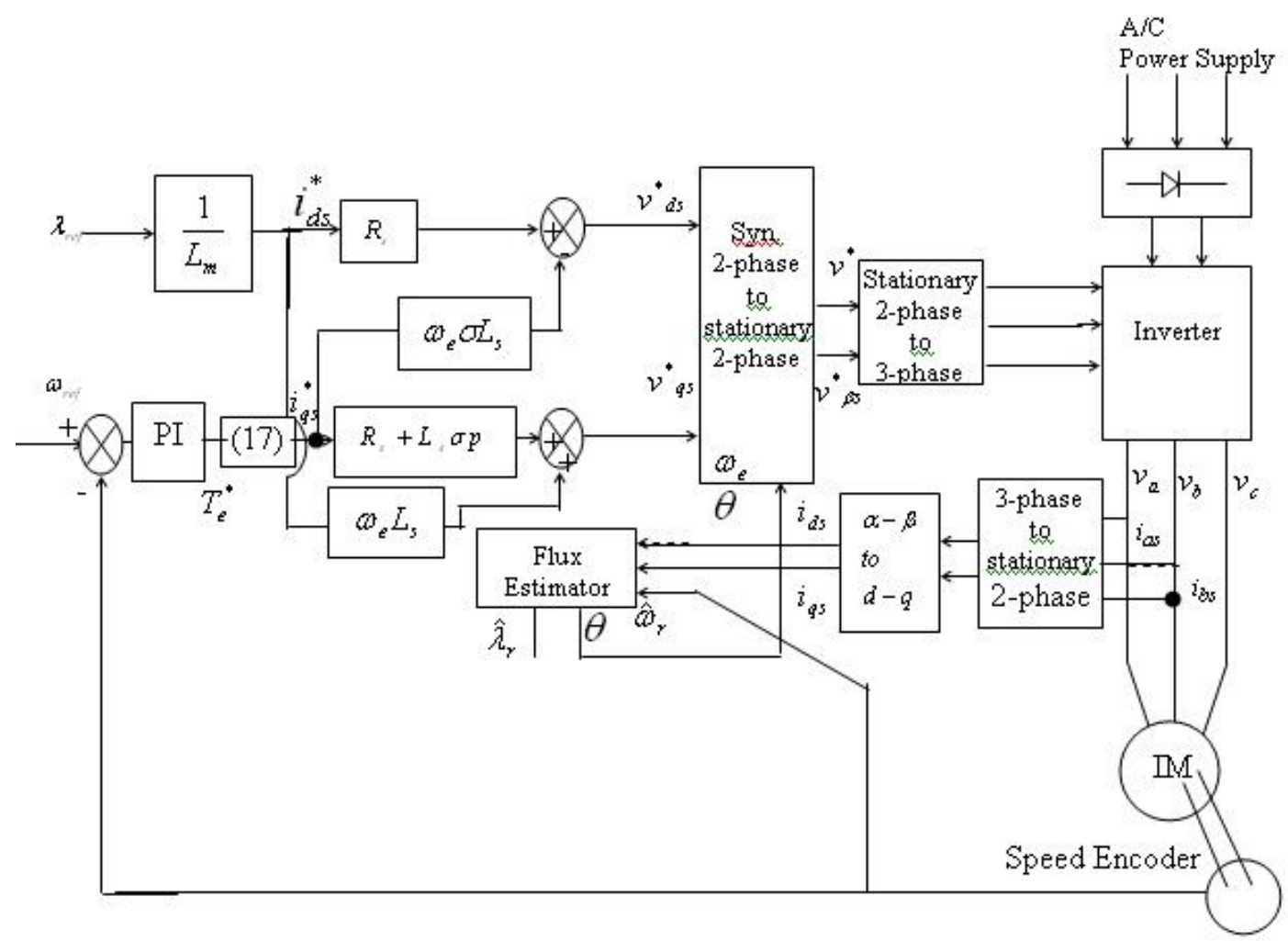

Fig 1. Proposed Induction motor control scheme

If the vector control is established such that $q$ axis rotor flux is set zero, and $d$-axis rotor flux is maintained constant then Eqn (11,12,9,10 and 6) becomes

$$
\begin{aligned}
\lambda_{d r} & =L_{m} i_{d s} \\
\omega_{s l} & =\frac{1}{T_{r}} \frac{i_{q s}}{i_{d s}} \\
i_{d r} & =0 \\
i_{q r} & =-\frac{L_{m}}{L_{r}} i_{q s} \\
T_{e m} & =\frac{3}{2} P_{p} \frac{L_{m}}{L_{r}} \lambda_{d r} i_{q s}
\end{aligned}
$$

where $T_{r}\left(=L_{r} / R_{r}\right)$ is the time constant of the rotor.

Hence, only q- axis stator current controls the electromagnetic torque.

Substituting Eqn (6) and rearrangement of Eqn (1) and Eqn (2), yields

$$
\begin{aligned}
& v_{d s}=R_{s} i_{d s}+\frac{L_{s}}{L_{m}} \frac{d \lambda_{d r}}{d t}-L_{m} \sigma \frac{d i_{d r}}{d t}-\omega_{e} \frac{L_{m}}{L_{r}} \lambda_{q r} \\
& -\omega_{e} \sigma L_{s} i_{q s}
\end{aligned}
$$

$$
\begin{aligned}
& v_{q s}=R_{s} i_{q s}+L_{s} \sigma \frac{d i_{q s}}{d t}+\omega_{e} L_{s} i d s+\frac{L_{m}^{2}}{L_{r}} \frac{d i_{q s}}{d t} \\
& +\omega_{e} L_{m} i_{d r}+L_{m} \frac{d i_{q r}}{d t}
\end{aligned}
$$

where, $\sigma=1-\frac{L_{m}^{2}}{L_{s} L_{r}}$.

Substituting Eqn (12), Eqn (15) and Eqn (16) into Eqn (18) and Eqn (19) yields

$$
\begin{aligned}
& v_{d s}=R_{s} i_{d s}-\omega_{e} \sigma L_{s} i_{q s} \\
& v_{q s}=R_{s} i_{q s}+L_{s} \sigma \frac{d i_{q s}}{d t}+\omega_{e} L_{s} i_{d s}
\end{aligned}
$$

\section{PROPOSED CONTROL SCHEME}

The stator command currents are obtained through the use of Eqn (13) and the PI control loop for speed error as follows

$$
\begin{aligned}
& i_{d s}^{*}=\frac{\lambda_{d r}^{*}}{L_{m}} \\
& i_{q s}^{*}=K_{P 2}\left(\omega_{r e f}-\omega_{r}\right)+K_{I 2} \int\left(\omega_{r e f}-\omega_{r}\right) d t
\end{aligned}
$$


The speed and the current loops are considered to be fast enough to assume that the actual stator currents are equal to their command inputs (i.e., $i_{\mathrm{ds}}=i_{\mathrm{ds}}^{*}$ and $\left.i_{q s}=i_{q \mathrm{~s}}^{*}\right)$. So the command voltage becomes

$$
\begin{aligned}
& v_{d s}^{*}=R_{S} i_{d s}^{*}-\omega_{e} \sigma L_{s} i_{q s}^{*} \\
& v_{q s}^{*}=R_{s} i_{q s}{ }^{*}+L_{s} \sigma \frac{d i_{q s}^{*}}{d t}+\omega_{e} L_{s} i_{d s}^{*}
\end{aligned}
$$

The block diagram of overall induction motor control system is shown in Fig. 1. The stationary to synchronous frame transformation block for the currents ( $\alpha-\beta$ to $d-q$ ), is given by

$$
\begin{aligned}
& i_{d s}=i_{\alpha s} \cos \theta+i_{\beta s} \sin \theta \\
& i_{q s}=i_{\alpha s} \sin \theta+i_{\beta s} \cos \theta
\end{aligned}
$$

The inverse transformation ( $d-q$ to $\alpha-\beta$ ) for the voltage components are given by

$$
\begin{aligned}
& v_{\alpha S}=v_{d s} \cos \theta-v_{q s} \sin \theta \\
& v_{\beta S}=v_{d s} \sin \theta+v_{q S} \cos \theta
\end{aligned}
$$

\section{ROTOR FLUX ESTIMATION}

The main problem of the integration in flux estimation as used in high performance electrical drives is the presence of dc biases, which affect the accuracy of the flux estimation. In particular dc drifts are always present in the signal before it is integrated, which causes the integrator to saturate with a resulting inadmissible estimation error. Moreover a dc bias also appears at the output of the integrator because of the initial conditions. Then it is necessary to remove the dc components of the signals both before and after they are integrated. An adaptive filter (ADALINE) as presented in [7] used as a notch filter to cut off the dc component adaptively.

Fig.2 shows the adaptive integrator with two identical neural notch filters before and after the pure integrator [7].

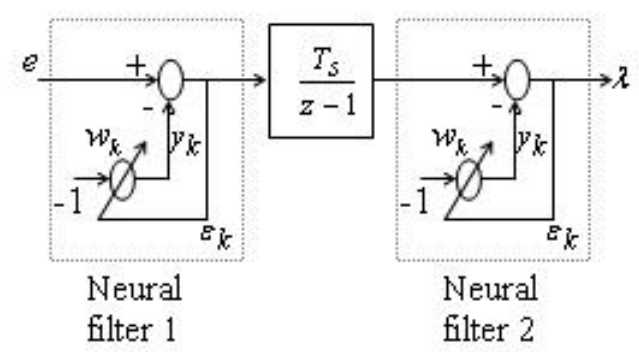

Fig. 2 Neural filter based integrator.

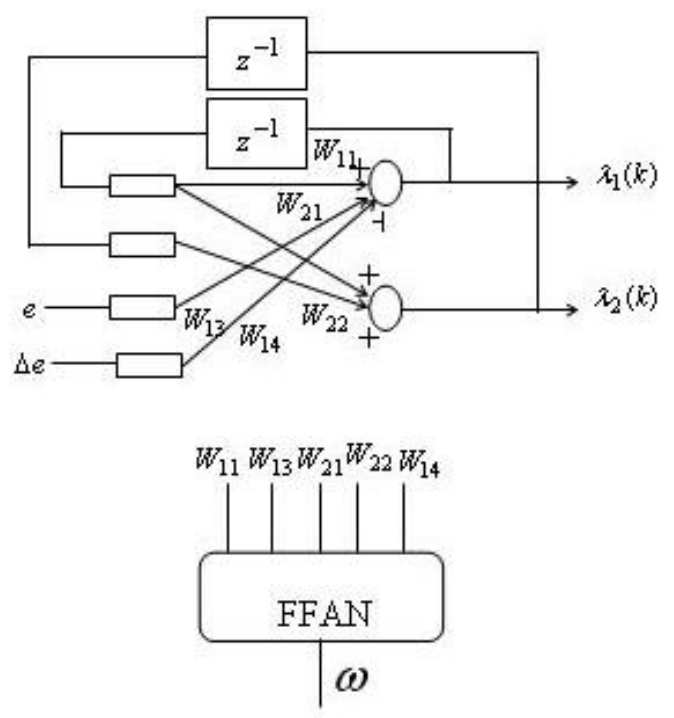

Fig. 3 Block diagram of the integration algorithm

The learning law of the neural adaptive filter is based on the algorithm suggested in [7], the fluxlinkage $\lambda$ is obtained from back e.m.f $e(k)$ by an integration method accomplished by programmable cascaded low-pass filter (PCLPF) implement by a hybrid neural network consisting of a recurrent neural network (RNN) and a feedforward artificial neural network (FFANN).

In the proposed algorithm rotor flux is estimated from both back emf $e(k)$ and and change of back emf $\Delta e(k)$.An equivalent RNN is then proposed which results in the following matrix equation: $\left[\begin{array}{c}\lambda_{1}(k+1) \\ \lambda_{2}(k+1)\end{array}\right]=\left[\begin{array}{cc}W_{11} & 0 \\ W_{21} & W_{22}\end{array}\right]\left[\begin{array}{l}\lambda_{1}(k) \\ \lambda_{2}(k)\end{array}\right]+\left[\begin{array}{c}W_{13} \\ 0\end{array}\right] e(k)$ $+\left[\begin{array}{c}W 14 \\ 0\end{array}\right] \Delta e(k)$

where $W_{11}, W_{21}, W_{22}, W_{13}$ and $W_{14}$ are the weights of the RNN, which is shown in Fig. 3.

\section{SIMULATION RESULTS}

Simulation studies have been conducted in order to establish the functionality of the proposed control scheme. The simulated induction motor is $3 \phi, 220 \mathrm{~V}, 1 \mathrm{hp}$. The model parameters for this motor are $P_{p}=2, R_{s}=1.798 \mathrm{ohm}, R_{r}=0.825$ ohm, $\quad L_{s}=L_{r}=0.08323$ henry, and 
$L_{m}=0.07613$ henry. The motor- load inertia and friction coefficient have been chosen to be $J=0.095 \quad$ Nm-sec $^{2}$ and $D=0.05 \quad$ Nm-sec, respectively.

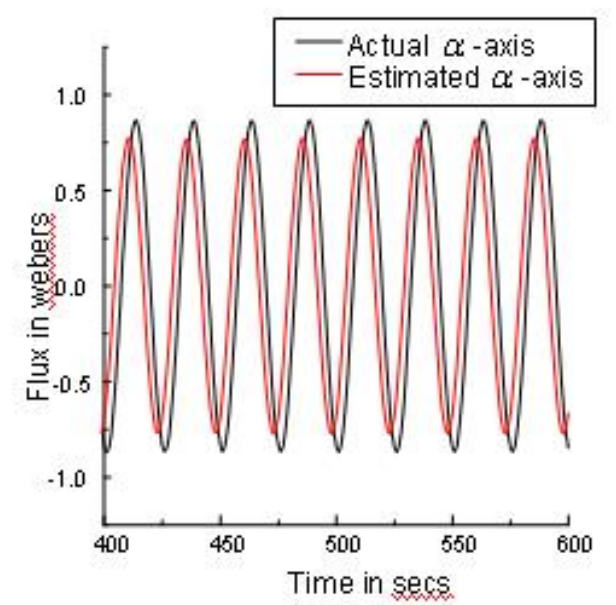

Fig. 4. $\alpha$-axis estimated flux by algorithm in [7]

Figures 4 and 5 show the estimated $\alpha$-axis rotor flux by the algorithm in [7] and the proposed methods respectively. The proposed technique is effective to reduce the phase difference. Similar results were found for $\beta$-axis rotor flux. Figure $6 \& 7$ present the $\mathrm{q}$-axis rotor flux and d-axis rotor current of proposed field orientation controller respectively. It is shown that proper field orientation is occurred. The speed response of proposed and conventional PI controller is shown in Fig. 8 in which flux angle is calculated as follows

$$
\theta=\int \omega_{e} d t
$$

It is shown that the response of proposed controller is faster.

Fig. 9 shows the speed response of proposed and conventional PI controller with proposed flux estimator. In the proposed technique, the overshoot of speed response is reduced.

Speed response for different set speeds is given in Fig. 10. The proposed control scheme follows the reference speed quickly as compared to PI controller.

The speed response with change of load at $t=5$ sec is given in figure 11. Sudden application of load torque causes a very small dip in the speed curve for the proposed method. On the other hand, the PI controller-based system shows a larger dip and speed oscillation. Figure 12 \& 13 show the effect of rotor and stator resistance respectively. The stator and rotor resistance was increased at $t=5 \mathrm{sec}$. It is shown that the proposed control scheme is less sensitive to parameter variation as compared to PI controller.

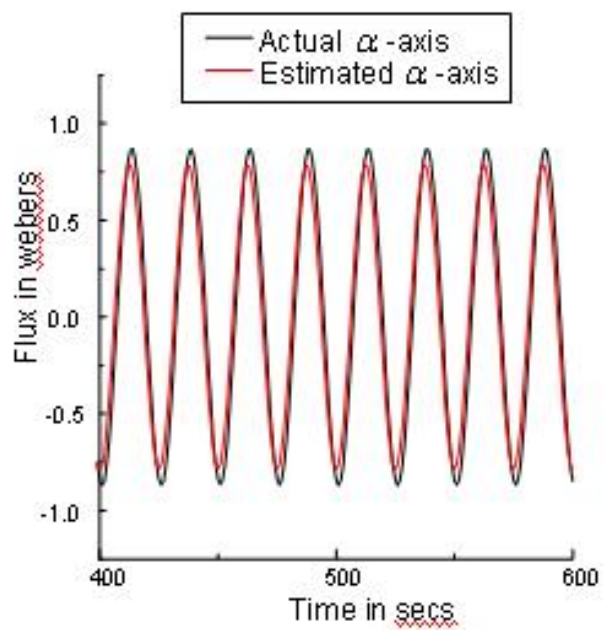

Fig. 5. $\alpha$ - axis estimated flux by proposed method

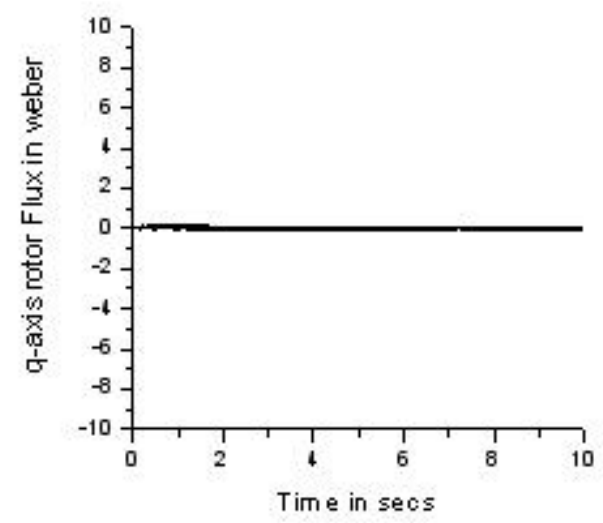

Fig.6. $q$ axis rotor flux of proposed control scheme

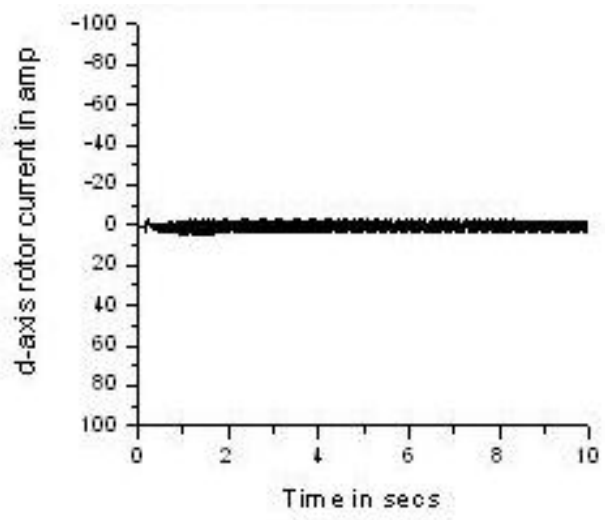

Fig.7. d-axis rotor current of Proposed Control Scheme 


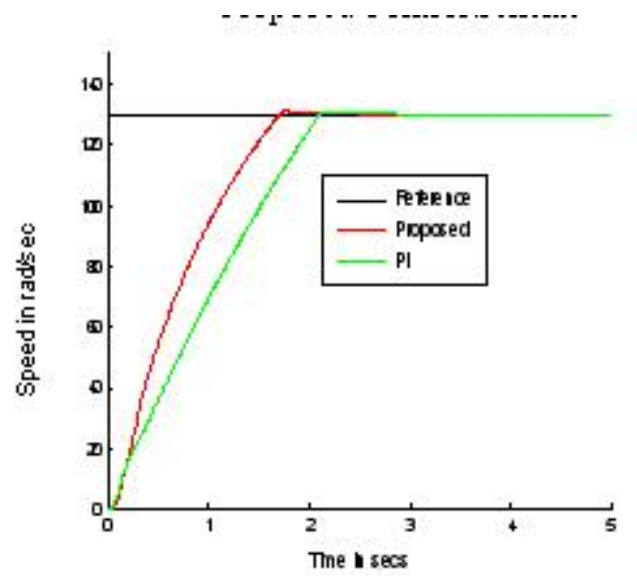

Fig. 8. Speed response with flux angle estimation from synchronous speed

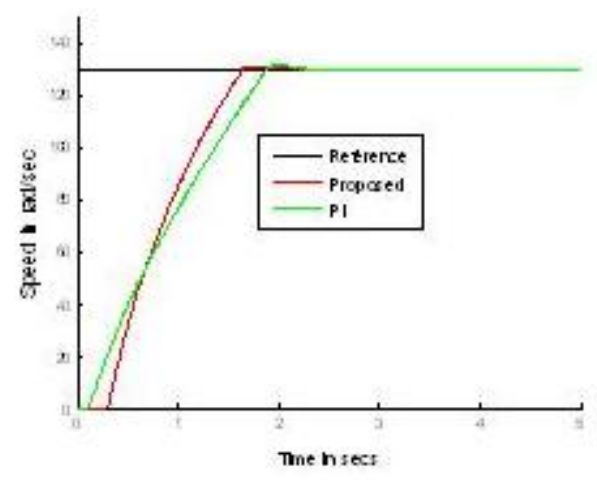

Fig.9. Speed response with proposed flux estimator

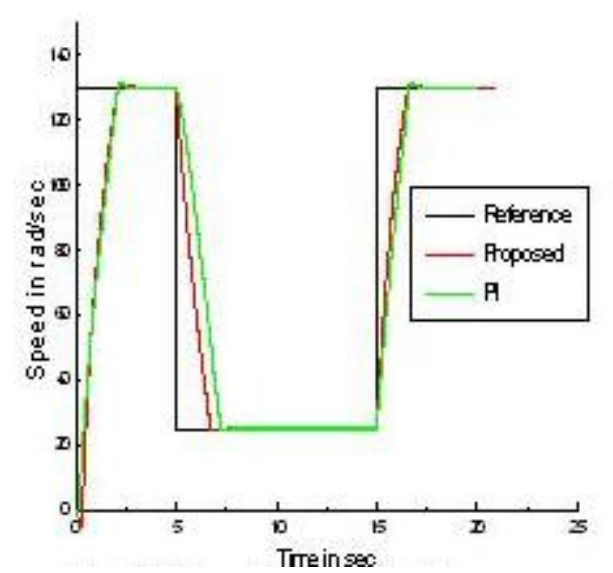

Fig 10. Speed response with proposed flux estimator for different set speed

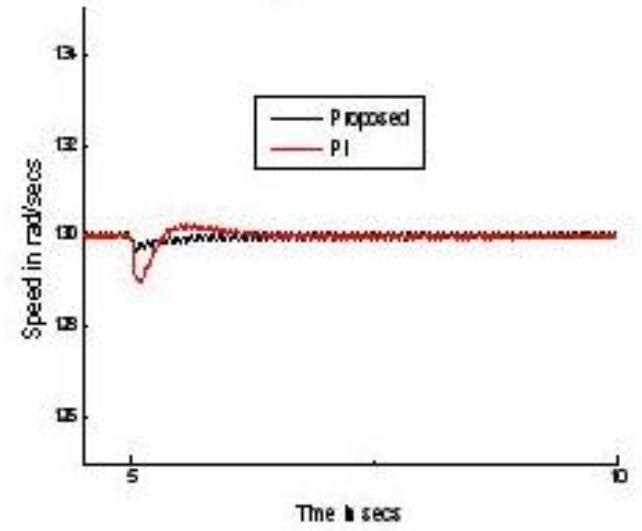

Fig.11. Speed response with proposed flux estimator for change in load torque

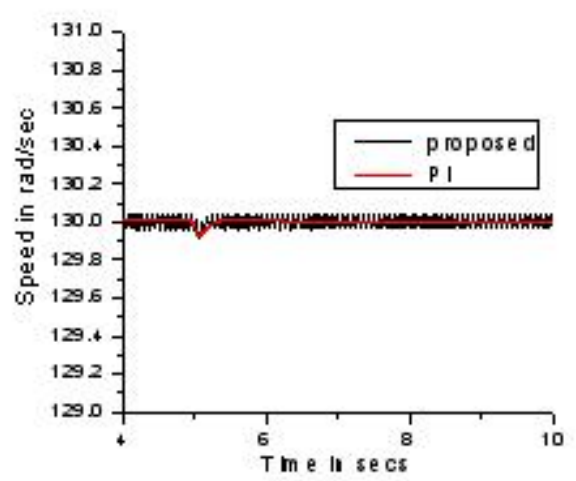

Fig.12. Speed response with change of rotor resistance

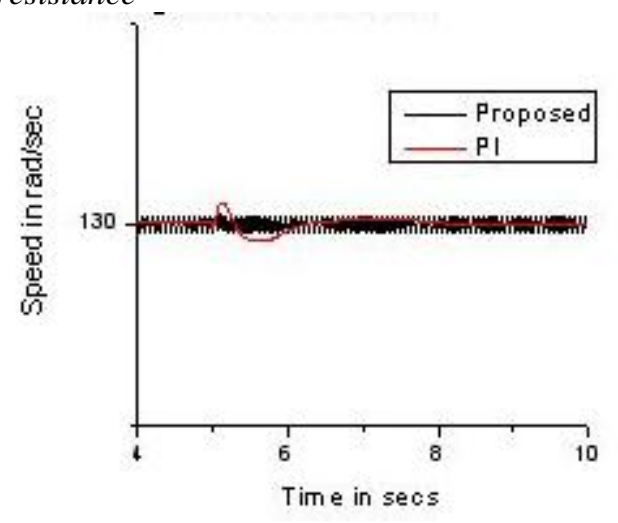

Fig.13. Speed response with change of stator resistance

\section{CONCLUSIONS}

In this paper a novel fast speed response control strategy for the poly-phase induction motor drive system based on flux angle is successfully developed. To improve the performance of the rotor flux estimator derivative term of the back 
emf in incorporated in the system. The obtained simulation results show that the proposed control scheme provides faster response than that of the conventional PI controller-based system.

\section{REFERENCES}

[1] F.Blaschke, 'The Principle of Field Orientation as Applied to the New Trans vector Closed Loop Control System for Rotating Field Machines", Siemens Review, vol. 34, pp. 217-220, 1972.

[2] K. Hasse, 'Zum dynamischen Verahalten der Asynchronmaschine bei Betrrieb mit variabler Staenderfrequenz und Staenderspannung” ("On the Dynamic Behavior of Induction Machines driven by Variable Frequency and Voltage Source"), ETZ-A, Bd 89 H.4, pp. 77-81, 1968.

[3] A Nabae, K. Otsuka, H. Uchino, \& R. Kurosawa, "An Approach to flux Control of Induction Motor Operated with Variable Frequency Power Supply”, IEEE Trans, Ind. Appl. vol. IA-16,pp.342-350, 1980.

[4] Bashudeb Chandra Ghosh "Parameter Adaptive Vector Controller for CSI-fed Induction Motor Drive and Generalized Approaches for Simulation of CSI-IM System" P.hd. Thesis Department of Electrical Engineering, IIT, Kharagpur, July, 1992.

[5] R. S. Cabera and J. Morales, "Some results about the Control and Observation of Induction Motors," in Proc. IEEE American Control Conf. vol. 3, pp. 1633-1637, 1995.
[6] Jun $\mathrm{Hu}$ and Bin Wu, “ New Integration Algorithms for Estimating Motor Flux over a Wide Speed Range." IEEE Trans. On Power Electron., vol. 13, No. 5, pp. 969977, September 1998.

[7] Maurizio Cirrincione, Marcello Pucci, Giamsalvo Cirrincione, and Gerard-Andre Capolino “ A new adaptive Integration Methodology for Estimating Flux in Induction Machine Drives.” IEEE Trans. Om Power Electronic. Vol. 19, no. 1, pp 2533, January 2004.

[8] Habib-ur Rehman, “ Elimination of the Stator Resistance Sensitivity and Voltage Sensor Requirement Problems for DFO Control of an Induction Machine.” IEEE Trans. on Industrial Electron., vol. 52, no. 1,pp.263269, February 2005.

[9] Young Ahn Kwon, and Sung Hwan Kim, “ A New Scheme for Speed-Sensorless Control of Induction Motor.” IEEE Trans. on Industrial Electron., vol. 51, no. 3, pp.545-550, June 2004.

[10] Haithem Abu-Rub, Jaroslaw Guzinski, Zbigniew Krzeminski, and Hamid A. Toliyat, " Advanced Control of Induction Motor Based on Load Angle Estimation." IEEE Trans. on Industrial Electron., vol. 51, no. 1, pp.5-13, February, 2004.

[11] Cristian Lascu and Andrzej M. Trzynadlowski, “ Combining the Principle of Sliding Mode, Direct Torque Control, and Space-Vector Modulation in a HighPerformance Sensorless AC Drive.” IEEE Trans. on Industry Applications, vol. 40,No. 1, pp. 170-177, January 2004. 